\title{
Computation of current-resistance photovoltaic model using reverse triangular number for photovoltaic emulator application
}

\author{
Razman Ayop, Chee Wei Tan, Kwan Yiew Lau \\ School of Electrical Engineering, Universiti Teknologi Malaysia, Malaysia
}

\begin{tabular}{l} 
Article Info \\
\hline Article historys: \\
Received Apr 26, 2019 \\
Revised May 3, 2019 \\
Accepted May 18, 2019 \\
\hline Keywords: \\
Boost converter \\
Buck converter \\
I-R PV model \\
Maximum power point tracking \\
(MPPT) \\
Photovoltaic (PV)
\end{tabular}

\section{Article historys:}

Received Apr 26, 2019

Revised May 3, 2019

Accepted May 18, 2019

\section{Keywords:}

I-R PV model

(MPPT)

\begin{abstract}
PV emulator (PVE) is a power supply that produces similar current-voltage (I-V) characteristic as the PV module. It simplifies the testing of the PV system during the development phase. Since the output voltage and current of the PVE change based on various factors (load, irradiance and temperature), the computation of the operating point for the PVE is crucial. The resistance feedback control strategy is a robust and fast approach to find the operating point for the PVE. Nonetheless, it uses an uncommon current-resistance PV model, which cannot be computed using the conventional approach. This work introduces the reverse triangular number to compute the PV model and obtained the operating point of the PVE. The reverse triangular number is based on the variable step sizes that allow fast computation of the PV model. The operating point is then used by the PI controller and the buck converter to produce the output voltage and current similar to the PV module. The results show that the reverse triangular number is able to compute the PV model accurately. In addition, the proposed PVE not only works well with resistive load but adapts accurately under the integration with maximum power point tracking converter.
\end{abstract}

Copyright (C) 2019 Institute of Advanced Engineering and Science. All rights reserved.

\section{Corresponding Author:}

Razman Ayop,

School of Electrical Engineering,

Faculty of Engineering, Universiti Teknologi Malaysia,

UTM Johor Bahru, 81310 Johor, Malaysia.

Email: razmanayop@gmail.com

\section{INTRODUCTION}

The deployment of solar energy has increased significantly the past few years. According to the Renewable 2017 Global Status Report, there had been a 75\% increase in solar photovoltaic (PV) global capacity in 2016 when compared to the previous year [1]. Much research has been done to improve the performance of the PV generation system. In this research, the PV modules are radiated with controlled artificial light to emulate the sunlight. Nonetheless, the approach is not efficient, which it requires a lot of power and large space. The alternative is to use PV emulator (PVE). The PVE is a power supply that generates current-voltage (I V) characteristic similar to the PV panel. The PVE is efficient, small in size and the ambient condition (irradiance and temperature) is easily adjusted. There are various PVE available in the market. Still, commercial PVE is very costly.

Various techniques have been introduced by previous researchers to bring down the cost of PVE. There are three main components of the PVE, which include the PV model, power converter and control strategy [2]. The PV model is commonly implemented using the direct calculation method [3] or the look up 
table (LUT) method [4]. The direct calculation method computes the PV model during the PVE operation, which requires low memory usage and allows various PV panel emulation (high adaptability). While the LUT method computes the PV model offline and uses the output data during the operation of the PVE. This method has a low computational burden, but requires a lot of memory to store the output data and it is difficult to emulate various PV panel models (low adaptability). The commonly used power converter for the PVE is the buck converter controlled using the proportional integral (PI) controller [5]. The linear regulator is also used in the PVE application [6]. This power converter has a fast response and contains no voltage ripple. However, the efficiency is very low and the controller is complex.

The function of the control strategy is to connect the PV model to the power converter while calculating the operating point of the PVE based on the load and the ambient conditions. The direct referencing method is the commonly used control strategy for the PVE [5]. It is easily implemented since there is no additional algorithm needed to compute the operating point. The control strategy is computed using the power converter inside the PVE. As the result, the design of the power converter and its controller affect the accuracy and consistency of the operating point [7]. The hybrid mode control strategy combines two types of direct referencing method in order to minimize the problem faced by the direct referencing method [7]. However, this approach results in a complex design of the PVE. The resistance comparison method is one of the control strategies that used a mathematical computation instead of relying on the power converter to compute the operating point [8]. This approach helps to improve the accuracy and consistency of the operating point. Nonetheless, the mathematical computation burdens the hardware platform used by the controller of the PVE.

The resistance feedback control strategy has the same advantages as the resistance comparison method with a much lower computation burden [9]. However, the resistance feedback control strategy requires a modified PV model called the current-resistance (I R) PV model, which is difficult to compute. The conventional I V PV model is computed quickly using the Newton Raphson method. However, the I R PV model fails to compute using the Newton Raphson method [9]. The LUT method can be used for the I R PV model instead of the direct calculation method to avoid this computation problem [10]. Nonetheless, there are many limitations when using the LUT method. The binary search method able to compute this PV model at a higher number of iterations, which results in a higher computation time [9]. Maintaining a low computation time is a priority for the PVE since it operates in real time and computation delays may result in inaccurate emulation. Therefore, a computational method needs to balance the computational time and the accuracy of the I R PV model for the PVE.

This article proposes a new computation approach called the reverse triangular number computation for the I R PV model. This PV model is implemented in the PVE's controller, which is based on the resistance feedback control strategy. The PVE consist of a buck converter controlled using the PI controller. The PV model is based on the single diode model. The performance of the PVE is determined using the resistive load as well as the maximum power point tracking (MPPT) boost converter with perturb and observe (P\&O) algorithm. The controller for both PVE and the MPPT converter are implemented in dSPACE ds1104.

\section{DESIGN OF PHOTOVOLTAIC EMULATOR}

The output voltage and current for the $\operatorname{PVE}\left(\mathrm{V}_{\mathrm{o} \_ \text {pve }}\right.$ and $\mathrm{I}_{\mathrm{o} \_ \text {pve }}$, respectively) are measured by the sensors and the output resistance for the PVE, $\mathrm{R}_{\mathrm{o} \text { p pve, }}$, is digitally calculated by the controller, as shown in Figure 1 . The I-R PV model used the $\mathrm{R}_{\mathrm{o} \_ \text {pve }}$ to produce the reference current for the PVE, $\mathrm{I}_{\text {ref pve. }}$ The $\mathrm{I}_{\text {ref } \_ \text {pve }}$ is compared with the $\mathrm{I}_{\mathrm{o} \_ \text {pve }}$ and the difference is fed into the PI controller. The PI controller produces the corresponding duty cycle for the PVE, $\mathrm{D}_{\text {pve }}$. The PWM generates the switching pulse in the form of gate-source voltage for the PVE, $V_{\text {gs_pve }}$ based on the $D_{\text {pve }}$. The PVE achieves steady state when the $I_{0 \_ \text {pve }}$ equal to the $I_{\text {ref_pve }}$.

\subsection{Current-Resistance Photovoltaic Model}

The PV characteristic equation of the I-R PV model is shown in (1) [9]. The photocurrent, $I_{\mathrm{ph}}$, and the saturation current, $I_{s}$, are calculated using (2) and (3), respectively. The parameters needed by the PV model are shown in Table 1 [11].

$$
\begin{aligned}
& I_{p v}=I_{p h}-I_{s}\left[\exp \left(I_{p v}\left(R_{p v}-R_{s}\right) / A_{f} V_{T}\right)\right]-I_{p v}\left(R_{p v}-R_{s}\right) / R_{p} \\
& I_{p h}=G / G_{s t c} \times\left[I_{s c}+\alpha\left(T-T_{s t c}\right)\right] \\
& I_{s}=\left[I_{s c}+\alpha\left(T-T_{s t c}\right)\right] /\left[\exp \left(V_{o c}+\beta\left(T-T_{s t c}\right) / A_{f} V_{T}\right)-1\right]
\end{aligned}
$$

where $I_{p v}$ is the PV current (A), (A), $R_{p v}$ is the PV resistance, $R_{s}$ is the series resistance, $A_{f}$ is the ideality factor, $\mathrm{V}_{\mathrm{T}}$ is the thermal voltage $\left(V_{T}=k T / q\right), \mathrm{k}$ is the Boltzmann constant $\left(1.38 \times 10^{-23} \mathrm{~J} / \mathrm{K}\right)$, $\mathrm{T}$ is the

Computation of current-resistance photovoltaic model using reverse triangular ... (Razman Ayop) 
temperature of $\mathrm{p}-\mathrm{n}$ junction $(\mathrm{K}), \mathrm{q}$ is the electron charge $\left(1.6 \times 10^{-19} \mathrm{C}\right), \mathrm{R}_{\mathrm{p}}$ is the parallel resistance, $\mathrm{G}$ is the irradiance $\left(\mathrm{W} / \mathrm{m}^{2}\right)$, STC is the standard test condition $\left(1000 \mathrm{~W} / \mathrm{m}^{2} 25^{\circ} \mathrm{C}\right), \mathrm{I}_{\mathrm{sc}}$ is the short circuit current $(\mathrm{A}), \alpha$ is the temperature coefficient of $\mathrm{I}_{\mathrm{sc}}, \mathrm{T}_{\mathrm{stc}}$ is the temperature at STC $\left(25^{\circ} \mathrm{C}\right), \mathrm{V}_{\mathrm{oc}}$ is the open circuit voltage $(\mathrm{V})$, and $\beta$ is the temperature coefficient of $V_{o c}$.
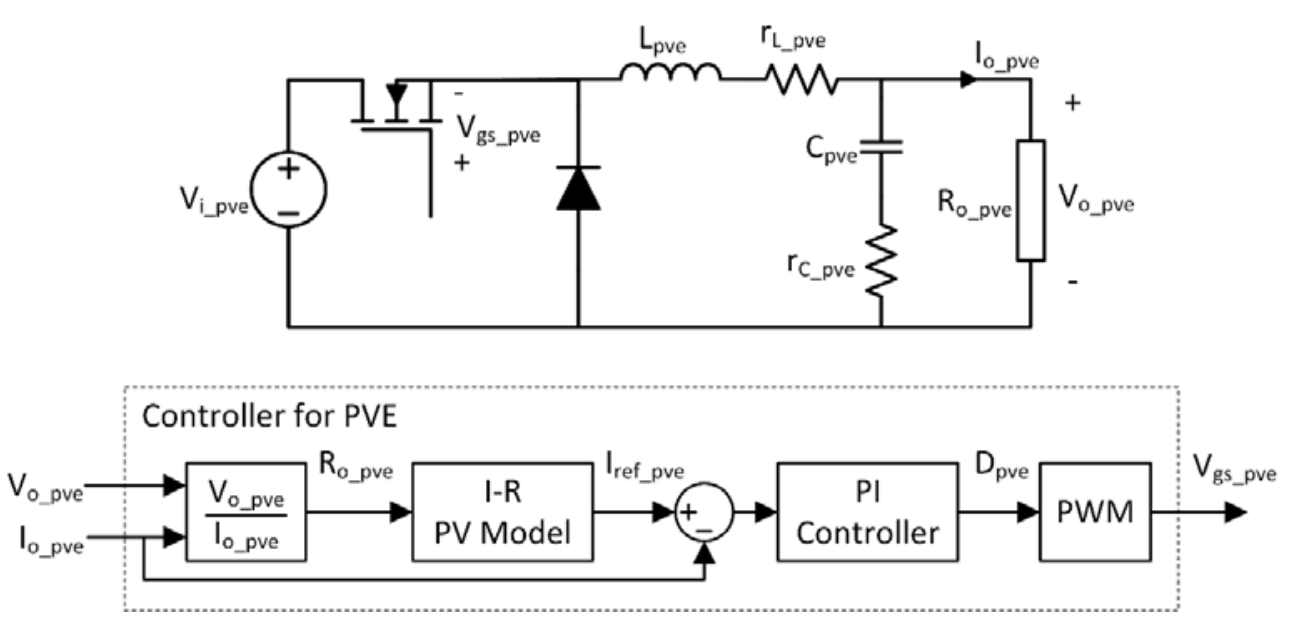

Figure 1. Block diagram of the PVE using the nonideal buck converter based on the resistance feedback control strategy

Table 1. The parameters of the ameresco 80J-B PV module at STC [11]

\begin{tabular}{cc}
\hline Parameter & Value \\
\hline Open circuit voltage, $\mathrm{V}_{\mathrm{oc}}$ & $44.4 \mathrm{~V}$ \\
Short circuit current, $\mathrm{I}_{\mathrm{sc}}$ & $2.32 \mathrm{~A}$ \\
Maximum power point voltage, $\mathrm{V}_{\mathrm{mp}}$ & $35.8 \mathrm{~V}$ \\
Maximum power point current, $\mathrm{I}_{\mathrm{mp}}$ & $2.23 \mathrm{~A}$ \\
Temperature coefficient of $\mathrm{V}_{\mathrm{oc}}, \beta$ & $-0.360 \% /{ }^{\circ} \mathrm{C}$ \\
Temperature coefficient of $\mathrm{I}_{\mathrm{sc}}, \alpha$ & $0.105 \% /{ }^{\circ} \mathrm{C}$ \\
Ideality factor, $\mathrm{A}_{\mathrm{f}}$ & 1.65 \\
Series resistance, $\mathrm{R}_{\mathrm{s}}$ & $1 \Omega$ \\
Parallel resistance, $\mathrm{R}_{\mathrm{p}}$ & $3500 \Omega$ \\
Number of series cell, $\mathrm{N}_{\mathrm{s}}$ & 72 \\
\hline
\end{tabular}

The computation of the I-R PV model is based on the reverse triangular number, which the implementation is shown in Figure 2. The computation starts by calculating the theoretical parameters shown in (2) and (3). Next, the per unit current, $i_{x}$, is calculated using (4). Initially, the location, $x$, is set to the maximum number of iterations, $\mathrm{N}$. The $\mathrm{N}$ needs to be a natural number $(1,2,3,4, \ldots)$. While the number of iterations, $n$, and the fixed status, $F$, are set to zero. The $\mathrm{I}_{\mathrm{pv}}$ is calculated using (5). This $\mathrm{I}_{\mathrm{pv}}$ is substituted into (6) to calculate the error of the iteration ( $\left.e_{i t e}\right)$, which is derived from (1). If the $e_{i t e}$ is larger than 0 and the $F$ is 0 , the $\mathrm{x}$ is updated based on the variable step sizes (based on the reverse triangular number) shown in (7). While if the $e_{i t e}$ is larger than 0 and the $F$ is 1 , the algorithm is ended. For other condition, the algorithm reduces the $\mathrm{x}$ using a fixed step size of 1 constant.

$$
\begin{aligned}
& i_{x}=2 I_{p h} /\left(N^{2}+N\right) \\
& I_{p v}=x i_{x} \\
& e_{i t e}=I_{p h}-I_{s}\left[\exp \left(I_{p v}\left(R_{p v}-R_{s}\right) / A_{f} V_{T}\right)\right]-I_{p v}\left(R_{p v}-R_{s}\right) / R_{p}-I_{p v} \\
& x=x+(N-n+1) \text { or } x_{n}=N n-n(n-1) / 2
\end{aligned}
$$

where $\mathrm{x}_{\mathrm{n}}$ is the $\mathrm{x}$ during the $\mathrm{n}^{\text {th }}$ iteration.

Indo. J. Elec. Eng. \& Inf, Vol.7, No. 2, June 2019: 314 - 322 


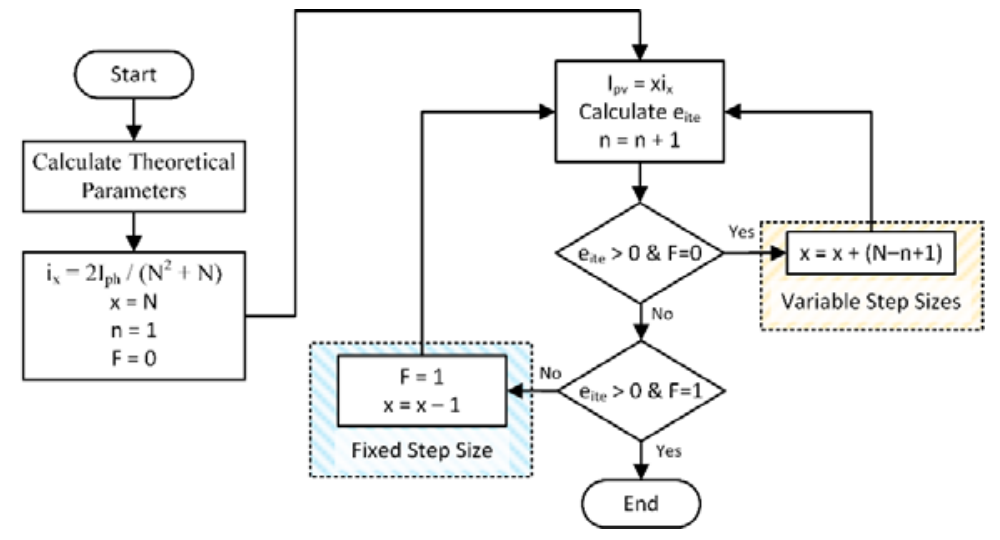

Figure 1. Computation of the I-R PV model based on the reverse triangular number

The advantage of using the reverse triangular number to compute the I R PV model is the ability to determine the sensitivity of the computation, $\rho$, based on the $\mathrm{N}$, which the $\rho$ is calculated using (8). The lower the $\rho$, the higher the accuracy of the I R PV model. To determine the $\mathrm{N}$ based on the $\rho$, the $\mathrm{N}$ is calculated using (9), which is derived from (8). In this research, the $\mathrm{N}$ chosen is 30 iterations, which the $\rho$ is 0.00215.

$$
\begin{aligned}
& \rho=2 /\left(N^{2}+N\right) \\
& N=4 / \rho(1+\sqrt{1+8 / \rho})
\end{aligned}
$$

\subsection{Buck Converter}

The circuit diagram for the buck converter is shown in Figure 1. The buck converter is designed to operate in the continuous current mode and produce output voltage ripple lower than $1 \%$ [12]. The parameters of the buck converter are listed in Table 2 . The PI controller, $G_{p i}$, is shown in (10). The tuning of the $G_{p i}$ requires the transfer function of the buck converter, $G_{b u c k}$, which is shown in (11) [13]. The $G_{p i}$ is tuned using the single input single output (SISO) tool in MATLAB/Simulink.

\begin{tabular}{|c|c|}
\hline Parameter & Value \\
\hline Input voltage for PVE, $V_{i \text { pve }}$ & $60 \mathrm{~V}$ \\
\hline Duty cycle for PVE, $D_{\text {pve }}$ & 0.05 to 0.80 \\
\hline Switching frequency for PVE, $\mathrm{f}_{\mathrm{s} \text { pve }}$ & $20 \mathrm{kHz}$ \\
\hline Inductance for PVE, $\mathrm{L}_{\text {pve }}$ & $1.75 \mathrm{mH}$ \\
\hline Internal resistance for $\mathrm{L}_{p v e}, \mathrm{r}_{\mathrm{L} \text { pve }}$ & $0.68 \Omega$ \\
\hline Capacitance for PVE, $\mathrm{C}_{\text {pve }}$ & $36 \mu \mathrm{F}$ \\
\hline Internal resistance for $\mathrm{C}_{\mathrm{pve}}, \mathrm{r}_{\mathrm{C} \text { pve }}$ & $0.26 \Omega$ \\
\hline Output resistance for PVE, $R_{\text {pve }}$ & $5 \Omega$ to $90 \Omega$ \\
\hline Proportional gain for PVE, $K_{p \text { p pve }}$ & 0.0062 \\
\hline Integral gain for PVE, $\mathrm{K}_{\mathrm{i} \text { pve }}$ & 85.26 \\
\hline
\end{tabular}

Table 1. The parameters of the buck converter and the PI controller

$$
\begin{aligned}
& G_{p i}(s)=K_{p}+K_{i} / s \\
& G_{\text {buck }}(s)=\frac{\hat{\imath}_{o}}{\hat{d}}=\frac{V_{i_{i} p v e}}{R_{O_{-} p v e}} \frac{1 / L_{p v e} C_{p v e}}{s^{2}+\left(1 / R_{O_{-} p v e} C_{p v e}\right) s+1 / L_{p v e} C_{p v e}}
\end{aligned}
$$

\subsection{Maximum Power Point Tracking Converter}

The MPPT boost converter shown in Figure 3 is a nonlinear variable load for the PVE and it is used to determine the capability of the proposed PVE to operate properly. This is important since the load for the PVE in the real application is commonly the MPPT converter. The MPPT converter is designed to operate in the continuous current mode with the input and output voltage ripple equal to $1 \%$ [14]. The parameters of the components in the MPPT converter is listed in Table 3. The measured $\mathrm{V}_{\mathrm{o} \_ \text {pve }}$ and $\mathrm{I}_{\mathrm{o} \text { ppe }}$ is used by the P\&O algorithm to determine the appropriate reference voltage for the MPT converter, $\mathrm{V}_{\text {ref mppt. The conventional }}$ $\mathrm{P} \& \mathrm{O}$ algorithm with a fixed step size is used for the MPPT converter [15]. The $\mathrm{V}_{\text {ref mpt }}$ is compared with the $\mathrm{V}_{\mathrm{o} \_ \text {pve }}$ and the difference is used by the PI controller to determine the duty cycle for the MPPT, $\mathrm{D}_{\text {mppt. }}$ The 
switching pulse is produced in the form of gate-source voltage for the MPPT converter, $\mathrm{V}_{\mathrm{gs}}$ mppt, which change the operation of the MPPT converter. This process is repeated until the PVE operates at the maximum power point (MPP).
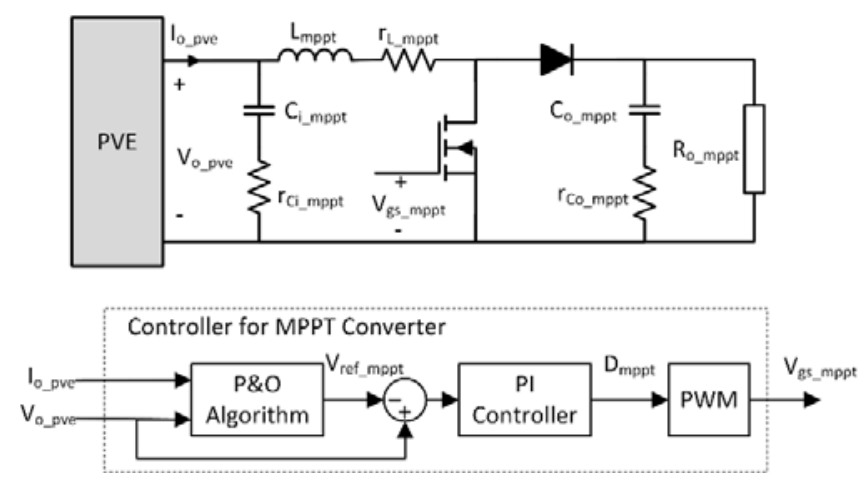

Figure 3. The block diagram of the nonideal MPPT boost converter based on the P\&O algorithm

Table 2. The parameters of the MPPT converter.

\begin{tabular}{|c|c|}
\hline Parameter & Value \\
\hline Input capacitance for MPPT Converter, $C_{i_{i} \text { mppt }}$ & $9.9 \mu \mathrm{F}$ \\
\hline Internal resistance for $\mathrm{C}_{\mathrm{i}_{-} \mathrm{mppt}}, \mathrm{r}_{\mathrm{Ci} \text { _mpt }}$ & $10.7 \Omega$ \\
\hline Output capacitance for MPPT Converter, $\mathrm{C}_{\mathrm{o}_{-} \mathrm{mppt}}$ & $47 \mu \mathrm{F}$ \\
\hline Internal resistance for $\mathrm{C}_{\mathrm{o}_{-} \mathrm{mppt}}, \mathrm{r}_{\mathrm{Co} \_ \text {mpt }}$ & $0.33 \Omega$ \\
\hline Inductance for MPPT Converter, $\mathrm{L}$ mpt & $4.46 \mathrm{mH}$ \\
\hline Internal resistance for $\mathrm{L}_{\mathrm{mppt}}, \mathrm{r}_{\mathrm{Lmppt}}$ & $0.83 \Omega$ \\
\hline Output resistance for MPPT converter, $\mathrm{R}_{\mathrm{o}_{-} \mathrm{mppt}}$ & $135 \Omega$ \\
\hline Duty cycle for MPPT converter, $\mathrm{D}_{\mathrm{mppt}}$ & 0.1 to 0.7 \\
\hline Switching frequency for MPPT converter, $\mathrm{f}_{\mathrm{s}_{-} \mathrm{mppt}}$ & $20 \mathrm{kHz}$ \\
\hline Proportional gain for MPPT converter, $K_{p_{-} \text {mppt }}$ & 0.0023 \\
\hline Integral gain for MPPT converter, $\mathrm{K}_{\mathrm{i} \text { mppt }}$ & 6.08 \\
\hline
\end{tabular}

\subsection{Experimental setup}

The experimental setup and its graphical user interface (GUI) are shown in Figure 4. The voltage and current sensors used for the PVE is the LEM LV25 and LY05, respectively. The sensors are designed to measure maximum $\mathrm{V}_{\mathrm{o} \text { pve }}$ and $\mathrm{I}_{\mathrm{o} \text { p pve }}$ of $60 \mathrm{~V}$ and $4 \mathrm{~A}$, respectively. The analogue to digital converter (ADC) included in dSPACE ds1104 is able to measure from $-10 \mathrm{~V}$ to $+10 \mathrm{~V}$. The measured voltages need to be calibrated using the linear regression to obtain the $\mathrm{V}_{\mathrm{o} \_ \text {pve }}$ and $\mathrm{I}_{\mathrm{o} \_ \text {pve }}$ reading. The PWM for the PVE and the MPPT converter are provided by dSPACE ds1104. The gate drivers are used to amplify the PWM outputs produce by dSPACE ds 1104 from $5 \mathrm{~V}$ to $15 \mathrm{~V}$. This is to ensure the $\mathrm{V}_{\mathrm{gs} \_ \text {pve }}$ and $\mathrm{V}_{\mathrm{gs} \_ \text {mppt }}$ able to switch the MOSFET appropriately. The sample time for dSPACE ds1104 requires $58 \mu$ s to compute the proposed controller.

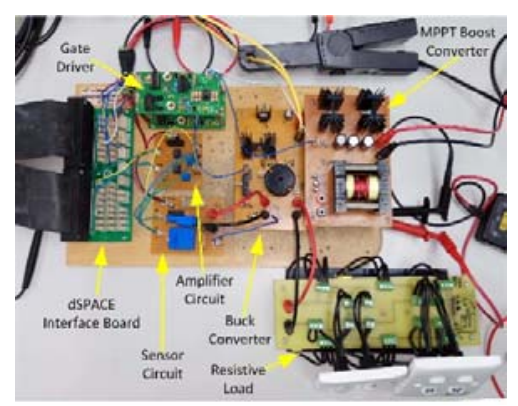

(a)

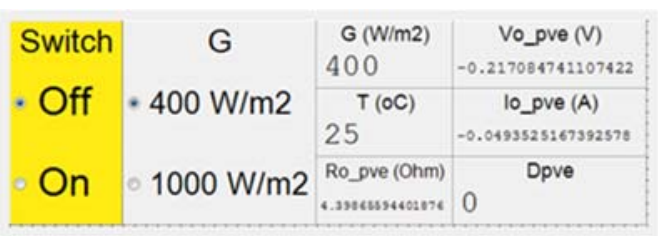

(b)

Figure 2. The overview of a) the experimental verification setup and b) the GUI to control PVE 


\section{RESULTS AND ANALYSIS}

Three results are shown to determine the performance of the proposed PVE. These results include the PV model test, resistive load test and the MPPT converter test. The PV model test is conducted to ensure the reverse triangular number algorithm able to compute the I-R PV model accurately. The resistive load test showed the ability of the proposed PVE to generate the I-V characteristic curve. The MPPT converter test determines the capability of the reverse triangular number algorithm to determine the operating point of the PVE when the $\mathrm{R}_{\mathrm{o} \_ \text {pve }}$ is inconsistent.

\subsection{PV Model Test}

The percentage error (current) of the PV model, $\mathrm{e}_{\mathrm{pvm}}$, is calculated using (12). The PV current based on the algebraic constraint, $\mathrm{I}_{\mathrm{pv} \_ \text {ac }}$, is used as the benchmark in calculating the error of the PV current based on the reverse triangular number algorithm, $\mathrm{I}_{\mathrm{pv} \_\mathrm{tn}}$. The algebraic constraint is a tool provided by MATLAB/Simulink to solve equation accurately. Nonetheless, this tool cannot be used for real-time application. Therefore, it is not implemented in the experimental setup.

$$
e_{p v m}=\left(I_{p v_{-} t n}-I_{p v_{-} a c}\right) / I_{p v_{\_} a c} \times 100 \%
$$

The $e_{p v m}$ is simulated for the $R_{0 \_p v e}$ ranging from $5 \Omega$ to $90 \Omega$ and the $\mathrm{G}$ is $400 \mathrm{~W} / \mathrm{m}^{2}$ and $1000 \mathrm{~W} / \mathrm{m}^{2}$ at $25^{\circ} \mathrm{C}$. The low $\mathrm{e}_{\mathrm{pvm}}$ shows a highly accurate PV model. The result shown in Figure 5 has the maximum $\mathrm{e}_{\mathrm{pvm}}$

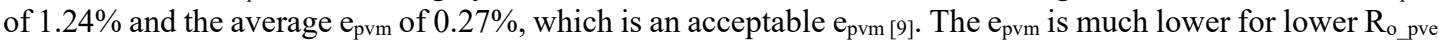
and $\mathrm{G}$.

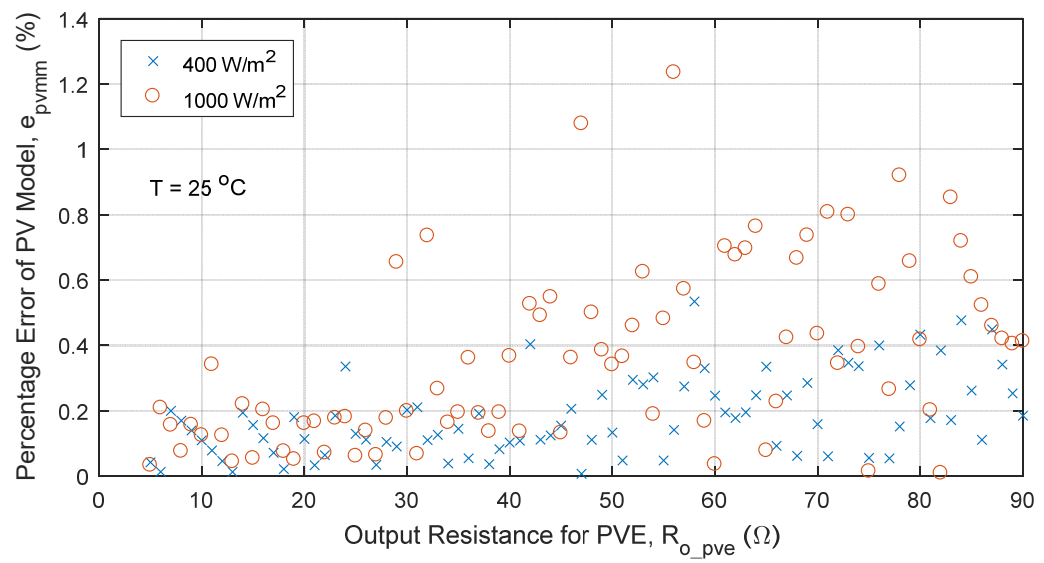

Figure 5. The $\mathrm{e}_{\mathrm{pvm}}$ at $25^{\circ} \mathrm{C}$

\subsection{Resistive Load Test}

The experimental $\mathrm{V}_{\mathrm{o} \_ \text {pve }}$ and $\mathrm{I}_{\mathrm{o} \_ \text {pve }}$ are compared with the $\mathrm{PV}$ voltage $\left(\mathrm{V}_{\mathrm{pv}}\right)$ and $\mathrm{I}_{\mathrm{pv}}$ from the PV model in the various condition. This comparison determines the capability of the proposed PVE to generate the I-V characteristic curve. Since the PV model shown in (1) is the I-R PV model, the term $\mathrm{V}_{\mathrm{pv}}$ is absent in the model. The $\mathrm{V}_{\mathrm{pv}}$ is calculated using (13).

$$
V_{p v}=I_{p v}-R_{p v}
$$

The $R_{o \_p v e}$ is changed from $10 \Omega$ to $90 \Omega$. While the $\mathrm{G}$ is $400 \mathrm{~W} / \mathrm{m}^{2}$ and $1000 \mathrm{~W} / \mathrm{m}^{2}$ at $25^{\circ} \mathrm{C}$. Based on Figure 6, the $\mathrm{V}_{\text {o p p ve }}$ and $\mathrm{I}_{\mathrm{o} \_ \text {pve }}$ able to follow the I-V characteristic curves of the PV model. This shows that the proposed PVE able to work properly with the resistive load. This is different from the direct referencing method, which unable to follow the I-V characteristic curve when the load and is high [9].

The open and short circuit tests are not conducted on the proposed PVE due to the limitation of the buck converter to regulate its output during these tests. Various points in the constant current region during $1000 \mathrm{~W} / \mathrm{m}^{2}$ are not tested due to the limitation of the PI controller. When the $\mathrm{I}_{\mathrm{o} \text { ppve }}$ is high and the $\mathrm{R}_{\mathrm{o} \text { ppve }}$ is low, the $\mathrm{V}_{\mathrm{o} \text { pve }}$ and $\mathrm{I}_{\mathrm{o} \_ \text {pve }}$ become oscillates. The oscillation is reduced by lowering the response of the PI controller. But, this reduces the performance of the PVE.

Computation of current-resistance photovoltaic model using reverse triangular ... (Razman Ayop) 


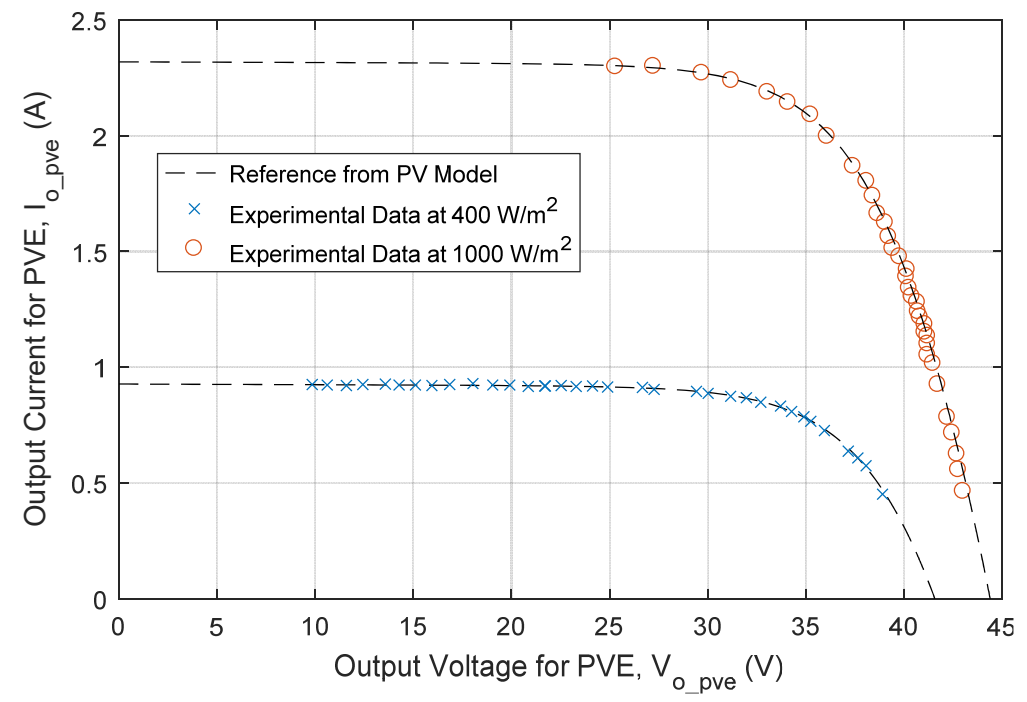

Figure 6. The experimental $\mathrm{V}_{\mathrm{o} \_p \text { pve }}$ and $\mathrm{I}_{\mathrm{o} \_ \text {pve }}$ mapped on the I-V characteristic curve of the PV model

\subsection{Maximum Power Point Tracking Test}

Experimental validation is conducted in order to determine the capability of the proposed PVE when connected to the MPPT converter. The $\mathrm{T}$ is kept constant at $25^{\circ} \mathrm{C}$ throughout the experiment. The $\mathrm{G}$ is started with $400 \mathrm{~W} / \mathrm{m}^{2}$ and step-changed to $1000 \mathrm{~W} / \mathrm{m}^{2}$ after $6.25 \mathrm{~s}$. This is done to assess the capability of the proposed PVE to operate when the G is stepped up. After $12.50 \mathrm{~s}$, the $\mathrm{G}$ is step-changed to $400 \mathrm{~W} / \mathrm{m}^{2}$ again for $6.25 \mathrm{~s}$. This is done to assess the capability of the proposed PVE to operate when the $\mathrm{G}$ decreases. The experimental result of the $\mathrm{V}_{\mathrm{o} \_ \text {pve }}$ and $\mathrm{I}_{\mathrm{o} \_ \text {pve }}$ when connected to the MPPT converter is shown in Figure 7.

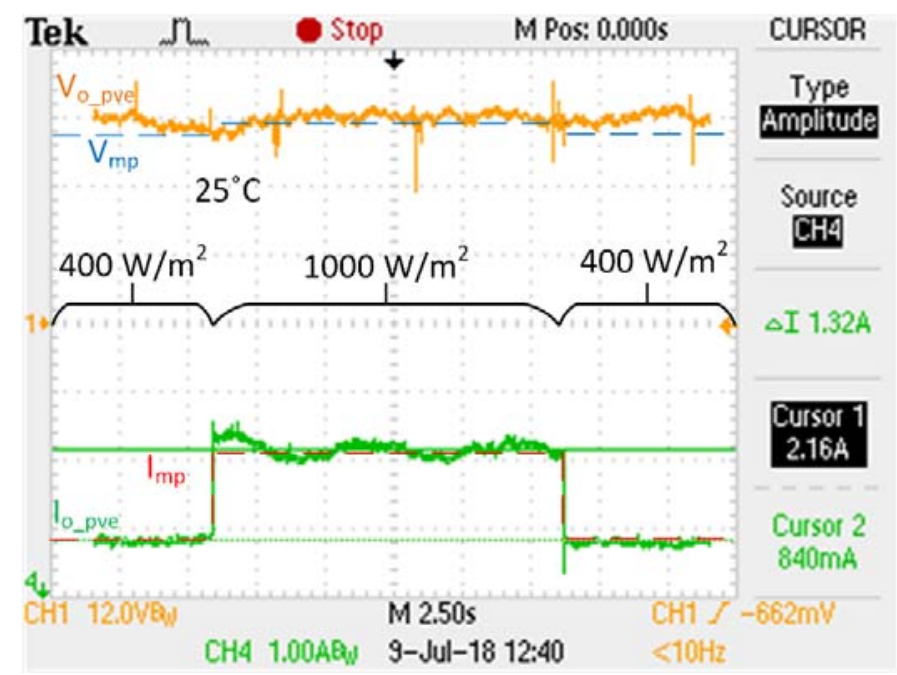

Figure 7. The experimental $\mathrm{V}_{\text {o_pve }}$ and $\mathrm{I}_{\mathrm{o} \_ \text {pve }}$ with the MPPT converter as the load

The $\mathrm{V}_{\mathrm{o} \_ \text {pve }}$ and $\mathrm{I}_{\mathrm{o} \_ \text {pve }}$ of the proposed PVE are compared with the PV model to determine the accuracy of the emulation with the MPPT converter. The maximum power point voltage and current $\left(\mathrm{V}_{\mathrm{mp}}\right.$ and $\left.\mathrm{I}_{\mathrm{mp}}\right)$ of the PV model at $400 \mathrm{~W} / \mathrm{m}^{2}$ are $33.21 \mathrm{~V} 0.84 \mathrm{~A}$, respectively. While the $\mathrm{V}_{\mathrm{mp}}$ and $\mathrm{I}_{\mathrm{mp}}$ of the PV model at $1000 \mathrm{~W} / \mathrm{m}^{2} 34.82 \mathrm{~V} 2.11 \mathrm{~A}$. Based on the result shown in Figure 7, the $\mathrm{V}_{\text {o_pve }}$ and $\mathrm{I}_{\mathrm{o} \text { p pve }}$ able to follow $\mathrm{V}_{\mathrm{mp}}$ and $I_{m p}$ at $400 \mathrm{~W} / \mathrm{m}^{2}$ and $1000 \mathrm{~W} / \mathrm{m}^{2}$. For the $\mathrm{G}$ at $400 \mathrm{~W} / \mathrm{m}^{2}$, the average $\mathrm{I}_{\mathrm{o} \_ \text {pve }}$ is $0.84 \mathrm{~A}$, which is similar to the $\mathrm{I}_{\mathrm{mp}}$ obtained from the PV model. While for the $\mathrm{G}$ at $1000 \mathrm{~W} / \mathrm{m}^{2}$, the average $\mathrm{I}_{\mathrm{o} \text { p pve }}$ is $2.16 \mathrm{~A}$, which is only 0.05 A higher compared to the $\mathrm{I}_{\mathrm{mp}}$ obtained from the PV model. Based on the $\mathrm{V}_{\mathrm{mp}}$ obtained from the PV model, 
the difference is only $1.61 \mathrm{~V}$, which is difficult to detect. Nonetheless, the average $\mathrm{V}_{\mathrm{o} \_ \text {pve }}$ obtained from the experiment is $34.54 \mathrm{~V}$, which is within the range of the $\mathrm{V}_{\mathrm{mp}}$ at $400 \mathrm{~W} / \mathrm{m}^{2}$ and $1000 \mathrm{~W} / \mathrm{m}^{2}$.

The capability of the proposed PVE to operate at the MPP is crucial. To determine whether the PVE operates at the MPP, the experimental $\mathrm{V}_{\mathrm{o} \_ \text {pve }}$ and $\mathrm{I}_{\mathrm{o} \_ \text {pve }}$ data obtained from the oscilloscope is mapped on the $\mathrm{P}-\mathrm{V}$ characteristic curve of the PV model, as shown in Figure 8 . The power at MPP, $\mathrm{P}_{\mathrm{mp}}$, obtained from the PV model for $400 \mathrm{~W} / \mathrm{m}^{2}$ and $1000 \mathrm{~W} / \mathrm{m}^{2}$ is $27.9 \mathrm{~W}$ and $73.4 \mathrm{~W}$, respectively. While the average output power for

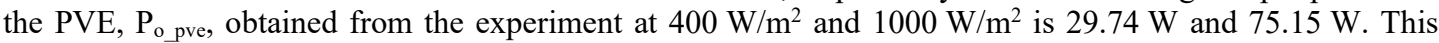
shows the proposed PVE is able to operate near to MPP when connected to the MPPT converter. The deviation between the experimental data and the reference from the PV model during $1000 \mathrm{~W} / \mathrm{m}^{2}$ is much larger compared to $400 \mathrm{~W} / \mathrm{m}^{2}$. This is due to the fixed voltage step size used in the P\&O algorithm for the MPPT converter. When the irradiance is low, the change in the $\mathrm{V}_{\text {ref_mpt }}$ results in a small change in $\mathrm{I}_{\text {o_pve. Nonetheless, }}$ when the irradiance is high, the similar change in the $\mathrm{V}_{\text {ref_mpt }}$ results in a large change in $\mathrm{I}_{\mathrm{o} \_ \text {pve, }}$ which is observed in Figure 7. The large change in the $I_{o}$ pve produces a large change in the $P_{o \text { pve }}$ at $1000 \mathrm{~W} / \mathrm{m}^{2}$, as shown in Figure 8. The similar effect is observed on the PVE using the direct referencing method connected to the MPPT converter with a constant step size P\&O algorithm $[5,9]$.

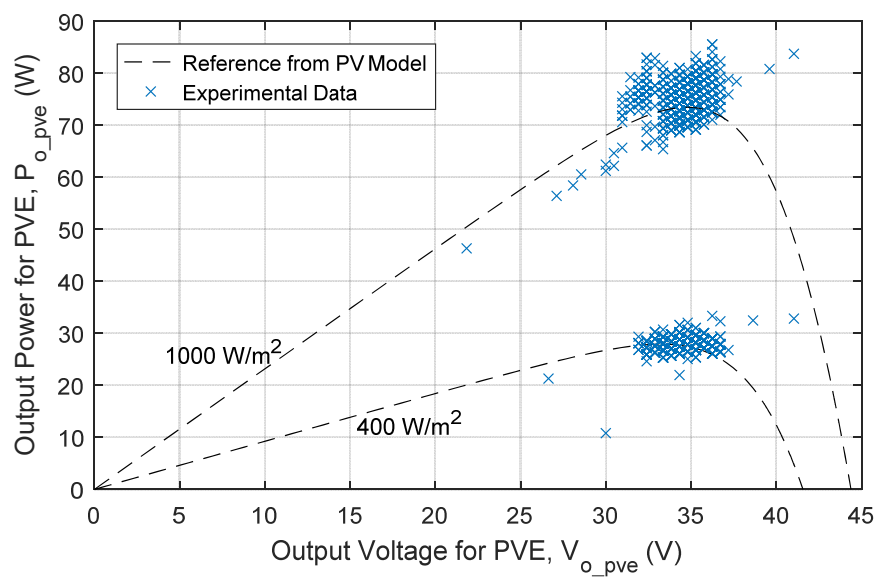

Figure 8. The experimental $\mathrm{V}_{\mathrm{o} \_ \text {pve }}$ and $\mathrm{I}_{\mathrm{o} \_ \text {pve }}$ mapped on the P-V characteristic curve of the PV model

\section{CONCLUSION}

The PVE using the resistance feedback control strategy has been elaborated in this article. This control strategy uses the I-R PV model, which cannot be computed using the common Newton-Raphson method. The reverse triangular number algorithm is proposed in order to compute the I-R PV model, which is then implemented into the proposed PVE. The result shows the proposed PV model is highly accurate and only has an average of $0.27 \%$ error. The proposed PVE able to generate the I-V characteristic curves precisely under various conditions. More importantly, it is also compatible with the PVE and able to achieve the MPP accurately.

\section{ACKNOWLEDGMENTS}

The authors would like to express gratitude to Ministry of Higher Education Malaysia (MOHE) for financial support and Universiti Teknologi Malaysia (UTM) for providing comprehensive library facilities. Funding provided by Universiti Teknologi Malaysia (UTM) is greatly appreciated. Lastly, thanks to colleagues who have either directly or indirectly contributed to the completion of this work.

\section{REFERENCES}

[1] REN21., "Renewables 2017 Global Status Report (GSR)," Renewable Energy Policy Network for the 21st Century (REN21) 17 June 2017, 2017.

[2] R. Ayop and C. W. Tan., "A comprehensive review on photovoltaic emulator," Renewable and Sustainable Energy Reviews, vol. 80, pp. 430-452, Dec 2017. 
[3] U. K. Shinde, S. G. Kadwane, R. K. Keshri, \& S. Gawande, "Dual Mode Controller-Based Solar Photovoltaic Simulator for True PV Characteristics," Canadia1n Journal of Electrical and Computer Engineering, vol. 40, pp. 237-245, 2017.

[4] Z. Weichao and J. W. Kimball., "DC-DC converter based photovoltaic simulator with a double current mode controller," in 2016 IEEE Power and Energy Conference at Illinois (PECI), pp. 1-6. 2016.

[5] L. P. Sampaio and S. A. O. d. Silva., "Graphic computational platform integrated with an electronic emulator dedicated to photovoltaic systems teaching," IET Power Electronics, vol. 10, pp. 1982-1992, 2017.

[6] S. Jin, D. Zhang, C. Wang, and Y. Gu., "Optimized Design of Space Solar Array Simulator with Novel Three-port Linear Power Composite Transistor Based on Multiple Cascaded SiC-JFETs," IEEE Transactions on Industrial Electronics, pp. 1-1, 2017.

[7] Y. Kim, W. Lee, M. Pedram \& N. Chang., "Dual-mode power regulator for photovoltaic module emulation," Applied energy, vol. 101, pp. 730-739, 2013.

[8] R. Ayop and C. W. Tan., "Improved control strategy for photovoltaic emulator using resistance comparison method and binary search method," Solar Energy, vol. 153, pp. 83-95, 1 Sep 2017.

[9] R. Ayop and C. W. Tan., "A novel photovoltaic emulator based on current-resistor model using binary search computation," Solar Energy, vol. 160, pp. 186-199, 2018.

[10] P. H. To and D. Q. Phan., "A photovoltaic emulator using dSPACE controller with simple control method and fast response time," in 2017 International Conference on System Science and Engineering (ICSSE), pp. 718-723. 2017.

[11] A. Solar., Ameresco Solar 80W (24V) Photovoltaic Modules - 80J-B (24V). ed: Ameresco Inc., 2014.

[12] D. W. Hart, Power Electronics. Valpar aiso University, Indiana: Tata McGraw-Hill Education, 2011.

[13] C. H. Balakishan and N. Sandeep., "Development of a Microcontroller Based PV Emulator with Current Controlled DC-DC Buck Converter " International Journal of Renewable Energy Research, vol. 4, pp. 1, Nov 2014.

[14] R. Ayop and C. W. Tan., "Design of boost converter based on maximum power point resistance for photovoltaic applications," Solar Energy, vol. 160, pp. 322-335, Jan 2018.

[15] N. A. Kamarzaman and C. W. Tan., "A comprehensive review of maximum power point tracking algorithms for photovoltaic systems," Renewable and Sustainable Energy Reviews, vol. 37, pp. 585-598, Sep 2014.

Indo. J. Elec. Eng. \& Inf, Vol.7, No. 2, June 2019: 314 - 322 